\title{
Pesticide use, erythrocyte acetylcholinesterase level and self-reported acute intoxication symptoms among vegetable farmers in Nepal: a cross-sectional study
}

\author{
Dinesh Neupane ${ }^{1,2^{*}}$, Erik Jørs ${ }^{3}$ and Lars Brandt ${ }^{3}$
}

\begin{abstract}
Background: As pesticide use is increasing and proper handling training is lacking, exposure to pesticides and intoxications are an important public health problems among farmers in developing countries. This study describes pesticide use among farmers and compares symptoms of possible acute intoxication and Erythrocyte Acetylcholinesterase(AChE) levels among vegetable farmers with a control group of blood donors in Nepal.

Methods: A cross-sectional study was carried out among 90 pesticide-exposed farmers and a control group of 90 blood donors. Participants were randomly selected and data were gathered through questionnaires, observation and blood test. Chi-square test, logistic regression and Student's t-test were used for data analysis to describe pesticide use and compare symptoms and AChE levels between the two groups. This study was approved by Nepal Health Research Council.

Results: The majority of pesticides used were WHO class II, classified as moderately hazardous. The mean numbers of personal protective equipment used by farmers were 2.22 ( $95 \% \mathrm{Cl}: 1.89 ; 2.54)$. Out of five hygienic practices asked, farmers followed 3.63 (95\% Cl: 3.40; 3.86) hygienic practices on the average. Farmers reported more symptoms of possible pesticide intoxication in the past month than did controls, mean 5.47 (95\% Cl: 4.70; 6.25) versus 2.02 (95\% Cl: 1.63; 2.40) ( $\mathrm{p}<0.05)$. The mean haemoglobin-adjusted $\mathrm{ACh}(\mathrm{Q})$ was significantly lower among farmers compared to controls, 28.92 (95\% Cl: 28.28; 29.56) $\mathrm{U} / \mathrm{g}$ versus 30.05 (95\% Cl: 29.51; 30.60) $\mathrm{U} / \mathrm{g},(\mathrm{p}=0.01)$. The risk of a farmer having lower $\mathrm{Q}$ level was about 3 times $(\mathrm{OR}=2.95 ; 95 \% \mathrm{Cl}: 1.16 ; 7.51)$ greater than controls.

Conclusion: Nepalese farmers exposed to pesticides have significantly more symptoms of possible pesticide intoxication than a control group of healthy individuals. A lower mean haemoglobin- adjusted AChE level was seen among farmers compared to the controls. The use of highly toxic pesticides, inadequate use of personal protective equipment and poor hygienic practices might explain the reason for symptoms of pesticide intoxication and a lower AChE level among farmers. Education and information of farmers should be undertaken to remediate these problems.
\end{abstract}

Keywords: Farmers, Carbamates, Erythrocyte acetylcholinesterase, Haemoglobin, Organophosphates, Pesticides, Nepal

\footnotetext{
* Correspondence: neupane.dinesh@gmail.com

'Unit of Health Promotion, University of Southern Denmark, Esbjerg, Denmark

${ }^{2}$ Nepal Development Society, Chitwan, Nepal

Full list of author information is available at the end of the article
} 


\section{Background}

Nepal is predominantly an agrarian country. The agricultural sector employs over $66 \%$ of the working population and contributes to $39 \%$ of the gross domestic product [1]. In the last five decades pesticide use has increased sharply in the pursuit of increasing agricultural production. A third of agriculture production is destroyed in pre- and post-harvest operations due to pest attacks in the field and storage [2]. Thus farmers use pesticides disproportionately to avoid pest attacks. The pesticide use at national level for the year 2008 was $151.2 \mathrm{~g}$ active ingredient per hectare of arable land [3]. Pesticides are not as extensively used in Nepal in terms of active ingredients used per hectare of cropland compared to many other countries [4]. However, pesticide use in Nepal in terms of location, intensity, target crops, types of chemicals and increasing consumption suggests a risk of significant exposures and intoxications among farmers [5,6].

The use of highly toxic pesticides is a major occupational risk among farmers in low income countries including Nepal [7]. Despite government's and donors' continuous efforts to promote Integrated Pest Management (IPM) [8] reliance on chemical pesticides has been growing in Nepal. Older, non-patented, more toxic, environmentally persistent and inexpensive chemicals are used extensively [9]. The safety measures recommended by Food and Agriculture Organisation of United Nation (FAO) are not followed in Nepal as in other low-income countries [10]. Few studies have been undertaken to explore different aspects of pesticides issues in Nepal [11,12]. One study reported lower Acetylcholinesterase(AChE), levels during the 'high pesticide use season' as compared to the 'low pesticide use season' [11], but non-exposed controls were not included. Studies from other parts of the world were mostly based on self-reported symptoms of acute intoxication, often without laboratory tests or non-exposed control groups [13-26].

The aim of this study is to describe the types of pesticides used, the use of Personal Protective Equipment (PPE), and hygienic practices among farmers. The study also compares self-reported symptoms in the past month and $\mathrm{AChE}$ levels between farmers and controls.

\section{Methods}

\section{Study design and setting}

A comparative cross-sectional survey was conducted by collecting data from vegetable farmers and a control group of blood donors of Chitwan district of Nepal from April to June 2012. Chitwan covers an area of 2,205 square kilometers and had a population of 579,984 in 2011 [27]. The district was chosen because it is one of the main commercial and intensive vegetable cultivation areas with a high volume of pesticide usage. Agriculture is the primary source of income for the population of the district [27].

\section{Sample size and selection of participants}

Most of the commercial vegetable farmers in Chitwan are associated to Fruit and Vegetable Farmers Cooperatives. A list of all Vegetable Farmers' Cooperatives was obtained from the District Agriculture Development Office. Membership lists were obtained from the respective cooperatives in order to find participants. The households to visit were selected in consultation with Farmers Cooperatives based on population proportion to size. Only male farmers who owned at least 10 katthas (0.168 hectares) of land, had used pesticides within a year, were engaged in vegetables production, did not have any other profession and did not report any known conditions that could influence on $\mathrm{AChE}$ levels (e.g. paroxysmal nocturnal haemoglobinuria, macrocytic anemia, microcytic anemia or use of pyridostigmine) were eligible to be participant. Controls were chosen from blood donors who were occupationally nonexposed to pesticides and they were matched for sex, age group and district.

The estimated study sample size was calculated based on AChE values obtained by J Gomes and et al. among desert farm workers in the United Arab Emirates [19]. For a desired 95\% confidence interval, considering alpha $=$ 0.05 and design effect $=1.5$, the sample size of 90 in each group was calculated to yield a power over $80 \%$.

\section{Data collection}

The investigator and a laboratory assistant visited each farmer to retrieve data by means of a questionnaire asked through face to face interview, observational checklist, height and weight measurement and blood test carried out on the same day. Information on demography, smoking habit, alcohol intake, type of pesticides used, use of PPE, hygienic practices and self-perceived symptoms were obtained from a questionnaire interview and an observational checklist which were developed by modifying the tools used to conduct a similar study in Bolivia [18]. For PPE, we asked availability and use of long-sleeve shirt, cap, mask, gloves, glasses, boot and gown and for hygienic practices we asked whether farmers often do practice hand washing with soap and water after spraying pesticides, changing clothes after spraying pesticides, hand washing with soap and water before eating during/after spraying pesticides, bathing whole body after spraying pesticide, smoking during a spraying session after handwashing with soap and water and immediate hand washing with soap and water after mixing pesticides. Regarding self-reported symptoms, we asked "Did you suffer from any of the following symptoms in the last month?" We also asked same question for them whether they experienced such symptoms immediately after spraying pesticides or not. We used WHO clinical symptoms of acute organophosphate and carbamates poisoning along with the previous Bolivian study to derive a list of symptoms [18,28]. Some 
of the symptoms were difficult for farmer's to report and therefore such clinical symptoms have been translated or combined into more understandable terms. The symptoms included in the questionnaire were: nausea, blurred vision, dizziness, skin allergy, excessive salivation, muscle cramp, headache, trembling hands, breathing difficulties, extreme tiredness, vomiting, abdominal pain, loss of appetite, lack of coordination, excessive sweating, difficulty in speaking and dry mouth.

The data for the control group were collected at the Regional Blood Transfusion Service Center, Bharatpur, Chitwan. They gave consent to participate in the study prior to screening for blood donation. The same questionnaire and measurements were used for controls. Literacy status was categorized in three categories (read easily, read with difficulty and cannot read) based on respondent capacity to read a sentence given during the interview.

Organophosphate or carbamate pesticides inhibit the blood enzymes AChE [29]. So, AChE measurement was taken for both farmers and control. Information on the level of AChE, Haemoglobin adjusted Erythrocyte Acetylcholinesterase Activity (Q) and haemoglobin was obtained from the blood test with the Test-mate ChE Cholinesterase Test System (Model 400) developed by EQM Research Inc [30]. In short, fingers were wiped with alcohol and then air-dried for about 30 seconds. Ten ml capillary blood was collected using a finger prick sterile lancing device and placed into the assay tube. AChE erythrocyte cholinesterase reagent was then dissolved in distilled water and inserted into the analyzer following the guidelines. The analyzer provided the reading for haemoglobin, AChE and Q, which were noted down in the same questionnaire. All laboratory tests were conducted in the field below $30^{\circ} \mathrm{C}$.

\section{Data analysis}

Data were entered in a database developed in Microsoft Access and imported to STATA 11 for analysis. For qualitative variables, chi-square test was used to see the difference between farmers and controls. Fisher's exact test was applied for some variables when expected frequency in each cell was less than 5. Data were analyzed as two independent samples from normal distributions based on the Student's T-test. Estimates are given with 95\% confidence intervals. Q was dichotomized into high and low categories. The cut-off point was one SD below the mean Q, i.e. at the 27.4. While selecting control and farmer we matched for five years age group (15-19, 2024 and so on). For example, 35 years of farmer might have 39 years of control. That is why; we found statistically significant difference in mean ages between control and farmers. So, age was adjusted in further analysis. Regression analyses were performed adjusting for body mass index, age and literacy.

\section{Ethical consideration}

Ethical approval for the study was obtained from Nepal Health Research Council. Written informed consent was obtained from all participating farmers and controls. Data were treated in a confidential manner with access only to the investigators and the laboratory assistant.

\section{Results}

\section{Characteristics of respondents}

The characteristics of farmers and controls are presented in Table 1. The average land area used for farming was 1.13 hectares and the average number of years involved in commercial vegetable farming was about 10 years. About $83 \%$ of the farmers had sprayed pesticides on an average of 6 hours during the week prior to the data collection date.

\section{Type of pesticides}

Organophosphate and carbamates were the most commonly used pesticides accounting for $66 \%$ of total pesticide use. Seven percent of pesticides belonged to organochlorine group. The remaining $27 \%$ were pyrethroid, macrocyclic lactone, anthranilicdiamide and unclassified. Seventy-one percent of farmers $(n=64)$ had pesticides in stock, and among them, each farmer had an average of 2 pesticides (range: 1 to 28). The top ten most common pesticides used by farmers are presented in Table 2 . Out of the total pesticides in stock, $21 \%$ had expired while expiration date was not mentioned in $19 \%$. Thus $41 \%$ of the stored pesticides were obsolete. When classified according to WHO criteria, $50 \%$ of pesticides were classified as moderately hazardous (II); $15 \%$ as highly hazardous (Ib) and $13 \%$ as slightly hazardous (III) categories. Only 6\% of pesticides were unlikely to represent any acute hazard (U) in normal use.

Nearly half of the interviewed farmers (44\%) had stored pesticides easily accessible by children, while $25 \%$ stored pesticide in a closed containers. Fifteen percent of the respondents stored pesticides in their farmhouse. About 7\%

\section{Table 1 Characteristics of respondents}

\begin{tabular}{lll}
\hline Variable & $\begin{array}{l}\text { Farmers } \\
(\mathbf{n = 9 0 )}\end{array}$ & $\begin{array}{l}\text { Control } \\
\mathbf{( n = 9 0 )}\end{array}$ \\
\hline Mean Age (years) & 41.83 & 38.36 \\
Respondent can easily read and write & $50 \%$ & $88 \%$ \\
Married respondents & $91 \%$ & $86 \%$ \\
Mean body mass index $\left(\mathrm{kg} / \mathrm{m}^{2}\right)$ & 21.41 & 25.18 \\
Smoking habit & $23 \%$ & $34 \%$ \\
Alcohol drinking habit & $65 \%$ & $33 \%$ \\
Mean land used by farmers (hectare)* & $1.13(0.87 ; 1.39)$ & \\
Involvement in vegetable farming (years) & $10.17(8.66 ; 11.69)$ & \\
Pesticide use years & $10.30(8.86 ; 11.73)$ & \\
\hline
\end{tabular}

Numbers in parenthesis are for $95 \% \mathrm{Cl}^{*}=86$ because 4 respondents were professional sprayer. 
Table 2 Ten most common pesticides used in the study area $(N=64)$

\begin{tabular}{|c|c|c|c|c|c|}
\hline Common name & Frequency & Percent & Chemical classification & Type of pesticide & WHO category \\
\hline Chlorpyriphos 50\% and Cypermethrin 5\% EC & 49 & 76 & Organophosphate + pyrethroid & Insecticide & $\|$ \\
\hline Imidaclorprid $17.8 \%$ & 33 & 51 & Organophosphate & Insecticide & $\|$ \\
\hline Flubendiamide & 17 & 29 & Anthranilicdiamide & Insecticide & $\mathrm{NL}$ \\
\hline Dichlorvos 76\% EC & 16 & 25 & Organophosphate & Insecticide & $\mathrm{lb}$ \\
\hline Propargite $70 \%$ EC & 13 & 20 & Unclassified & Insecticide & III \\
\hline Endosulfan & 13 & 20 & Organochlorine & Insecticide & $\|$ \\
\hline Methomyl 40 & 12 & 18 & Carbamate & Insecticide & $\mathrm{IB}$ \\
\hline Mancozeb & 11 & 17 & Dithiocarbamate & Fungicide & U \\
\hline Emamectin Benzoate & 10 & 17 & Macrocyclic Lactone & Insecticide & III \\
\hline Cypermethrin 10\% & 10 & 17 & Pyrethroid & Insecticide & $\|$ \\
\hline
\end{tabular}

Note: Only pesticides found during the home visit were recorded.

respondents stored pesticides in the kitchen and the same percentage stored pesticides in the sleeping room. About $36 \%$ of the farmers stored pesticides in the ceiling of their animal shed in a polythene bag. It was observed that all pesticides were stored in original boxes/containers.

\section{Use of personal protective equipment and hygienic practices}

A total of $13 \%$ farmers did not use any PPE while spraying pesticides in the field. On an average, farmers used about 2 PPE. Cap was the most commonly used protective measure (64\%) followed by long sleeved shirt (56 \%). About $46 \%$ farmers used dust mask to protect against pesticide while spraying in the field and 33\% farmers used long legged trousers or pants. The percentage of respondents who used glass, gowns, boots and gloves was less than $10 \%$. Through observation, it was confirmed that $95 \%$ of farmers had long sleeve shirts, $63 \%$ of them possessed a mask, $31 \%$ had gloves and $21 \%$ had boots. The mean number of PPE used was 2.22 (95\% CI: $1.89 ; 2.54)$. Fifty percent of those who could read easily used more than 2 PPE compared to $26 \%$ who did not, $(p<0.01)$. No significant differences was seen for different age groups as $73 \%$ of those whose age was less than the mean age ( 41.83 years) used more than 2 PPE compared to $66 \%$ of those whose age was higher than the mean age $(\mathrm{p}=0.30)$.

Of the 5 hygienic practices, farmers on the average followed 3.63 (95\% CI: 3.40; 3.86). Forty percent of the farmers $(\mathrm{n}=36)$ washed their hands with soap and water immediately after mixing pesticides while $96 \%$ respondents washed their hands after spraying pesticides. Seventy-two percent $(n=65)$ of the interviewees replied that they washed their hands after spraying pesticides before eating. Those respondents who did not wash their hands before eating after spraying in the field were mostly putting chewing tobacco in their mouth. About $70 \%$ of the respondents washed their whole body after finishing spraying pesticides. Similarly, more than $84 \%$ of the farmers changed their clothes when they finished spraying in the field. Four percent respondents mentioned that they sprayed pesticide with the wind direction. Twothird of the farmers reported that their sprayer leaked. Among smokers, only 50\% washed their hands before smoking. Sixty percent of those who could read easily used more than 2 hygienic practices as compared to $32 \%$ of those who could not read easily, ( $\mathrm{p}<0.01)$. Likewise, 37\% of those younger than the mean age ( 41.8 years) practiced more than 2 hygienic practices compared to $48 \%$ of those above the mean age ( 41.8 years), $(\mathrm{p}=0.13)$.

One in two respondents either sold empty pesticide bottles to Kawadi (ragpickers) or disposed them in a municipality container. None of the respondents reported that they reused empty pesticide containers/bottles/ bags/boxes. However, $44 \%$ respondents said that they threw the containers in the field, around the houses or nearby rivers. Twelve percent of the farmer's burnt the empty used pesticide bottles/bags/containers. We did not find any statistically significant association between ability to read and correct method of disposal.

\section{Possible acute intoxication symptoms}

On the average, farmers reported 4.78 (95\% CI: 4.05; 5.52) possible symptoms of acute intoxication in the previous month compared to the controls, who reported 1.58 (95\% CI: $1.25 ; 1.92)(\mathrm{p}<0.05)$ (Table 3). Farmers reported about 7.28 (95\% CI: 6.40; 8.16) symptoms immediately after handling pesticides throughout their lifetime. The most often reported symptoms among farmers in the previous month were blurred vision (50\%) and extreme tiredness (47\%). Those who experienced symptoms immediately after spraying when farming were more likely to have experienced symptoms in the past month $(\mathrm{p}<0.01)$. Logistic regression analysis adjusted for age, body mass index and literacy showed odds ratio consistently higher among farmers as compared to controls [Table 4]. The highest 
Table 3 Reported symptoms by farmers (in the last month and immediately after pesticide use) and controls (in the last month)

\begin{tabular}{|c|c|c|c|c|}
\hline \multirow[t]{2}{*}{ Symptoms } & \multicolumn{3}{|c|}{ In the last month } & \multirow{3}{*}{$\begin{array}{l}\text { Ever experienced any } \\
\text { symptoms immediately } \\
\text { after pesticide use } \\
\text { Farmers (\%) }\end{array}$} \\
\hline & $\begin{array}{l}\text { Farmers } \\
(\%)\end{array}$ & $\begin{array}{l}\text { Controls } \\
(\%)\end{array}$ & P-value & \\
\hline & $(n=90)$ & $(n=90)$ & & \\
\hline Nausea & 25 & 8 & $<0.01$ & 47 \\
\hline $\begin{array}{l}\text { Blurred } \\
\text { vision }\end{array}$ & 50 & 16 & $<0.01$ & 70 \\
\hline Dizziness & 34 & 6 & $<0.01$ & 56 \\
\hline Skin Allergy & 25 & 17 & 0.159 & 50 \\
\hline $\begin{array}{l}\text { Excessive } \\
\text { Salivation }\end{array}$ & 3 & 3 & $1.0^{x}$ & 5 \\
\hline $\begin{array}{l}\text { Muscle } \\
\text { cramps }\end{array}$ & 40 & 16 & $<0.01^{x}$ & 51 \\
\hline Headache & 40 & 8 & $<0.01$ & 55 \\
\hline $\begin{array}{l}\text { Trembling } \\
\text { hands }\end{array}$ & 24 & 8 & $<0.01$ & 33 \\
\hline $\begin{array}{l}\text { Difficulty in } \\
\text { breathing }\end{array}$ & 21 & 4 & $<0.01^{x}$ & 30 \\
\hline $\begin{array}{l}\text { Extreme } \\
\text { tiredness }\end{array}$ & 47 & 20 & $<0.01$ & 70 \\
\hline Vomiting & 6 & 1 & $0.11^{x}$ & 20 \\
\hline $\begin{array}{l}\text { Abdominal } \\
\text { pain }\end{array}$ & 23 & 5 & $<0.01$ & 36 \\
\hline $\begin{array}{l}\text { Loss of } \\
\text { appetite }\end{array}$ & 24 & 6 & $<0.01$ & 35 \\
\hline $\begin{array}{l}\text { Lack of } \\
\text { coordination }\end{array}$ & 22 & 5 & $<0.01$ & 31 \\
\hline $\begin{array}{l}\text { Excessive } \\
\text { sweating }\end{array}$ & 43 & 17 & $<0.01$ & 61 \\
\hline $\begin{array}{l}\text { Difficulty in } \\
\text { speaking }\end{array}$ & 8 & 1 & $0.03^{x}$ & 18 \\
\hline Dry mouth & 35 & 7 & $<0.01$ & 46 \\
\hline
\end{tabular}

${ }^{x}=$ Fisher's exact test.

and lowest odds ratios were observed for the variables 'lack of coordination' $(\mathrm{OR}=6.27)$ and 'loss of appetite' $(\mathrm{OR}=1.74)$ respectively (Table 4$)$.

There was no statistically significant difference between farmers and controls in terms of health care seeking behavior. Out of 90 farmers, 87 (97\%) felt sick in the previous month, and $45(50 \%)$ of them visited health care facility whereas out of 90 control, 57 (63\%) felt sick in the previous month, and $65 \%$ of them visited health care facility. Among 140 respondents who had reported that they felt sick in the last month prior, 83 were farmers and 57 were controls. Among them, about $50 \%$ of the farmers and $65 \%$ of the controls visited a health care facility. Sickness self-management during illness was higher among controls (29\%) as compared to farmers (22\%).
Table 4 Odds ratio for the self reported symptoms among farmers $(n=90)$ as compared to controls $(n=90)$ in the past month

\begin{tabular}{ll}
\hline Symptoms & OR $(\mathbf{9 5 \%} \mathbf{C l})$ \\
\hline Nausea & $3.10(1.01-9.55)$ \\
Blurred vision & $7.25(2.65-19.80)$ \\
Dizziness & $3.54(1.18-10.56)$ \\
Skin Allergy & $1.77(0.70-4.42)$ \\
Muscle cramps & $3.36(1.33-8.51)$ \\
Headache & $5.03(1.82-13.85)$ \\
Trembling hands & $2.49(0.78-8.03)$ \\
Extreme tiredness & $2.58(1.10-6.07)$ \\
Abdominal pain & $1.86(0.53-6.45)$ \\
Loss of appetite & $1.74(0.48-6.28)$ \\
Lack of coordination & $6.27(1.64-23.99)$ \\
Excessive sweating & $3.32(1.27-8.69)$ \\
Dry mouth & $5.06(1.72-14.86)$ \\
\hline
\end{tabular}

Note: Adjusted for age, body mass index and literacy. Not included in analysis: salivation, breathing difficulties, vomiting and speak difficulties because of few values in each cells.

\section{Acetyl cholinesterase levels}

$\mathrm{AChE}$, heamoglobin and Q levels were significantly lower among farmers as compared to the controls. Logistic regression analysis adjusting for body mass index, age, literacy status and alcohol showed that a farmer's risk of having a lower $\mathrm{Q}$ level is about 3 times $(\mathrm{OR}=2.95$; $95 \%$ CI: 1.16 ; 7.51) the risk of the controls. Though, participants who reported at least one acute intoxication symptom had -1.02(95\% CI: $-2.06 ; 0.028)$ unit less $\mathrm{Q}$ as compared to those who did not report any acute intoxication symptoms from linear regression analysis, there was no statistically significant association between participants reporting at least one acute intoxication symptoms and $\mathrm{Q}$ (Table 5).

\section{Discussion}

This study found widespread use of moderately hazardous pesticides WHO class II and limited use of proper PPE and hygienic practices. An earlier study among Nepali farm workers showed low levels of pesticide handling practices when using pesticides even though the majority of farmers were knowledgeable about possible pesticide

Table 5 Mean AChE level of farmers and control

\begin{tabular}{llll}
\hline Variables & \multicolumn{2}{l}{ Mean $(\mathbf{9 5 \%} \mathrm{Cl})$} & P-value \\
\cline { 2 - 3 } & Farmers & Control & \\
\hline AChE $(\mathrm{U} / \mathrm{mL})$ & $3.35(3.24 ; 3.45)$ & $3.64(3.53 ; 3.75)$ & $<0.01$ \\
$\mathrm{Q}(\mathrm{U} / \mathrm{g})$ & $28.92(28.28 ; 29.56)$ & $30.05(29.51 ; 30.60)$ & $<0.01$ \\
Haemoglobin $(\mathrm{g} / \mathrm{dL})$ & $11.58(11.32 ; 11.84)$ & $12.12(11.81 ; 12.44)$ & $<0.01$ \\
\hline
\end{tabular}


harm [11]. The infrequent use of PPE has been reported by studies conducted in other low-income countries as well $[13,18,20-22]$. Studies mentioned that the low use of PPE may be due to low education level, lack of training, low income, pesticide dealers not promoting/selling PPE, limited awareness and discomfort [13,18,20-22]. The use of dust masks, caps and long-sleeve shirts by the majority of farmers means that farmers are willing to wear them might signal their willingness to adopt other, more evidencebased measures. This could be taken as an opportunity to introduce similar but more effective equipment for prevention of pesticide exposure among farmers. With the exception of hand washing with soap after spraying limited hygienic practices were found among farmers similar to studies from Cambodia [21] and Ethiopia [26] but in contrast to studies from Bolivia [18] and Oman [22].

We found that farmers had more symptoms in the past month compared to controls. Some of this excess may be related to pesticide exposure, but could also be due to dehydration, exhaustion from work and other factors. Symptoms related to heavy work and lack of fluids (sweating, difficulty breathing, thirst) were also higher among farmers compared to control. Inadequate PPE use, poor hygienic practices and the use of highly toxic pesticides have probably increased pesticide exposure and related symptoms as other study found that the use of protective measures was associated with fewer intoxication symptoms after handling pesticides [18]. Other studies have consistently reported more symptoms among pesticideusing farmers as compared to controls, results that support our finding of pesticides probably being responsible for the excess symptoms among the farmers compared to controls $[14,18,19]$. We could not find statistically significant association between reported acute intoxication symptoms and decreased Q level. This could be because our exposure measurement was crude and symptoms were self-reported by participants. A study found that cholinesterase inhibition was associated with symptoms from the respiratory system, eyes and central nervous system among farmers [14]. Thus, the significantly lower AChE level among farmers compared to controls further suggests that the symptoms could partly be due to pesticide exposures. Though the majority of farmers mentioned that they had at least one possible symptom of acute intoxication during one month prior to our interview, $50 \%$ of them visited the health facility to seek care. However, there is a lack of specific training among health professionals regarding pesticide intoxication.

Our study supports the finding that farmers in developing countries do not store pesticides in safe places and that children may have easy access to them. Studies conducted in Nepal, Oman and Cambodia showed similar result $[11,21,22]$. Easy access by children means that children are at a higher risk of accidental intoxication. Pesticides stored in the sleeping room, kitchen, shed, store room and in the attics are easy accessible when needed - but also provides easy access when suicide is contemplated. Many studies have shown that easy access to pesticides is directly linked to suicides [31]. In addition evidence suggests that restricting access to lethal pesticides significantly reduces suicide rates [32]. Another major problem described in our study was the improper disposal of used pesticide containers, which might lead to environmental pollution and intoxications. This finding is similar to studies from other countries though some differences were observed concerning disposal methods [20,22,33]. A case-control study showed that exposure to used containers containing pesticides was associated with an increased birth defect risk [34].

\section{Limitations}

Controls had no known pesticide exposure. However, they might have been exposed to pesticides due to living near farms where pesticide was used, while passing through sprayed or more likely from contaminated food. However, this would lead to bias toward the null.

The use of blood donors as controls is likely to introduce selection bias as blood donors generally healthier than the general population. Nepal blood transfusion services follow are as per WHO advocacy and recommendations, which is based on voluntary non-remunerated regular blood donation, which will minimized the any potential bias that the controls could have a lower socio-economic status [35]. The study tried to minimize these limitations by matching for sex and geographical region when recruiting controls and by adjusting for age in the multivariate analysis. Recall bias on the part of farmers cannot be ruled out as information was obtaining through interviews.

\section{Conclusions}

Nepalese farmers exposed to pesticides have significantly more symptoms of possible pesticide intoxication than a control group of healthy individuals. A lower mean haemoglobin- adjusted AChE level was seen among farmers compared to the controls. The use of highly toxic pesticides, inadequate use of personal protective equipment and poor hygienic practices might explain the reason for symptoms of pesticide intoxication and a lower AChE level among farmers. In spite of many years of promoting IPM to Nepali farmers there is still an urgent need for educating farmers in improved pesticide handling techniques and IPM alternatives to protect the health of themselves and their families.

\section{Abbreviations}

AChE: Erythrocyte Acetylcholinesterase; FAO: Food and Agriculture Organisation of United Nation; IPM: Integrated Pest Management; PPE: Personal protective equipment; Q: Haemoglobin adjusted Erythrocyte Acetylcholinesterase Activity; WHO: World Health Organisation. 


\section{Competing interests}

The authors declare that they have no competing interests.

\section{Authors' contributions}

DN, EJ and LB conceived and designed the study. DN collected the data and performed statistical analysis. DN, EJ and LB drafted the manuscript. All authors read and approved the final version of the manuscript.

\section{Acknowledgement}

Our special thanks goes to Mr. Deepak Neupane from Nepal Red Cross Society, Chitwan for providing technical assistance during field survey and laboratory test. We are also thankful for Danish Society for Occupational and Environmental Health and DIALOGOS for their generous support and Department of Occupational and Environmental Medicine, Odense University Hospital for partial funding of the study. We are also thankful to Shakun Sharma, Anshu Varma, Rajan Sharma, Rupesh Gautam and Shiva Raj Mishra for providing valuable comments on our draft manuscript, assisting on finalizing the manuscript and helping to make additional analysis. This original article is based on corresponding author's master thesis report entitled "Pesticide exposure and its health effect among farmers in Nepal" for partial fulfillment of Master of Science in public health at University of Southern Denmark, Denmark.

\section{Author details}

${ }^{1}$ Unit of Health Promotion, University of Southern Denmark, Esbjerg, Denmark. ${ }^{2}$ Nepal Development Society, Chitwan, Nepal. ${ }^{3}$ Clinic of Occupational Medicine, Odense University Hospital, Odense, Denmark.

Received: 16 May 2014 Accepted: 7 November 2014 Published: 20 November 2014

\section{References}

1. Government of Nepal, Ministry of Agriculture Development, Department of Agriculture: Welcome to Department of Agriculture. Kathmandu: Department of Agriculture; 2014. http://www.doanepal.gov.np/. Accessed 20.08.2014.

2. Palikhe BR: Challenges and options of pesticide use: in the context of Nepal. Landschaftsökologie und Umweltforschung 2002, 38:130-141.

3. Atreya K, Sitaula BK: Mancozeb: growing risk for agricultural communities. Himalaya J Sci 2010, 6(8):9-10.

4. FAOSTAT: Pesticide use: Food and Agriculture Organisation of the United Nations 2014. http://faostat.fao.org/site/424/DesktopDefault.aspx? PagelD=424 - ancor.

5. Baker SL, Gyawali BK: Promoting Proper Pesticide use in Nepal, Volume 28. Kathmandu: Ministry of Agriculture and Winrock International; 1994.

6. Plant Protection Directorate: Annual Progress Report. Kathmandu: Ministry of Agriculture Development; 2003. http://ppdnepal.gov.np/index.php? option=document\&id=14.

7. Wesseling C, Aragon A, Castillo L, Corriols M, Chaverri F, de la Cruz E, Keifer M, Monge P, Partanen TJ, Ruepert C, van Wendel de Joode B: Hazardous pesticides in Central America. Int J Occup Environ Health 2001, 7:287-294.

8. Plant Protection Directorate: National IPM Program in Nepal. Kathmandu: Ministry of Agriculture; 2013. http://ppdnepal.gov.np/index.php? option=cms\&id=19.

9. Ecobichon DJ: Pesticide use in developing countries. Toxicology 2001, 160:27-33.

10. FAO: International Code of Conduct on the Distribution and Use of Pesticides, Food and Agriculture Organization of the United Nations (FAO). Italy: FAO; 2002. http://www.fao.org/docrep/005/y4544e/y4544e00.htm.

11. Atreya K, Sitaula BK, Overgaard H, Bajracharya RM, Sharma S: Knowledge, attitude and practices of pesticide use and acetylcholinesterase depression among farm workers in Nepal. Int J Environ Health Res 2012, 22(5):401-415.

12. Shrestha P, Koirala P, Tamrakar AS: Knowledge, practice and use of pesticides among commerical vegetable growers of Dhading district, Nepal. J Agri Environ 2010, 11:95-100.

13. Kishi M, Hirschhorn N, Djajadisastra M, Satterlee LN, Strowman S, Dilts R: Relationship of pesticide spraying to signs and symptoms in Indonesian farmers. Scand J Work Environ Health 1995, 21(2):124-133.

14. Ohayo-Mitoko G, Kromhout H, Simwa J, Boleij J, Heederik D: Self reported symptoms and inhibition of acetylcholinesterase activity among Kenyan agricultural workers. Occup Environ Med 2000, 57(3):195-200.
15. Yassin M, Abu M, Safi J: Knowledge, attitude, practice and toxicity symptoms associated with pesticide use among farm workers in the Gaza Strip. Occup Environ Med 2002, 59(6):387-393.

16. Mancini F, Bruggen AHV, Jiggins $J$, Ambatipudi AC, Murphy H: Acute pesticide poisoning among female and male cotton growers in India. Int J Occup Environ Health 2005, 11(3):221-232.

17. Catano HC, Carranza E, Mani CH, Hernandez AF: Plasma cholinesterase levels and health symptoms in Peruvian farm workers exposed to organophosphate pesticides. Arch Environ Contam Toxicol 2008, 55(1):153-159.

18. Jørs E, Morant RC, Aguilar GC, Huici O, Lander F, Baelum J, Konradsen F: Occupational pesticide intoxications among farmers in Bolivia: a cross-sectional study. Environ Health 2006, 2006(21):5-10.

19. Jomes J, Lloyd O, Revitt DM, Norman JN: Erythrcyte cholinesterase activity levels in desert farm workers. Occup Med 1997, 47(2):90-94.

20. Khan DA, Shabbir S, Majid M, Naqvi TA, Khan FA: Risk assessment of pesticide exposure on health of Pakistani tobacco farmers. J Expo Sci Environ Epidemiol 2010, 20:196-204.

21. Jensen $H$, Konradsen F, Jørs E, Petersen JH, Dalsgaard A: Pesticide use and selfreported sysmptoms of acute pesticide posioning among aquatic farmers in Phnom Penh, Cambodia. J Toxicol 2011, 2011:639814. doi:10.1155/2011/639814.

22. Esechie JO, Ibitayo O: Pesticide use and related health problems among greenhouse workers in Batinah Coastal Region of Oman. J Forensic Leg Med 2011, 18(5):198-203.

23. Osten JR, Epomex C, Tnoco-Qjanquren R, Soares AM, Guilhermino L: Effect of pesticide exposure on acetylcholinesterase activity in subsistence farmers from Compeche, Mexico. Arch Environ Health 2004, 59(8):418-425.

24. Sivayoganathan C, Gnanachandran S, Lewis J, Fernando M: Protective measure use and symptoms among agropesticide applicators in Sri Lanka. Soc Sci Med 1995, 40(4):431-436.

25. Magauzi R, Mabaera B, Rusakaniko S, Chimusor A, Ndlovu N, Tshimanga M, Shambira G, Chadambuka A, Gombe N: Health effects of agrochemicals among farm workers in commercial farms of Kwekwe district, Zimbabwe. Pan Afr Med J 2011, 9:26.

26. Mekonnen Y, Agona TW: Pesticide sprayers's knowledge, attitude and practices of pesticide use on agricultural farms of Ethiopia. Occup Med 2002, 52:311-315.

27. District Development Committe Chitwan: District profile of Chitwan (In Nepali). Chitwan: 2011. http://www.ddcchitwan.gov.np/.

28. Thundiyil JG, Stober J, Besbelli N, Pronczuk J: Acute pesticide poisoning: a proposed classification tool. Bull World Health Organ 2008, 86(3):205-209.

29. Coye MJ, Lowe JA, Maddy KT: Biological monitoring of agricultural workers exposed to pesticides. J Occup Med 1986, 28:619-627.

30. EQM Research Inc: Test-mate ChE Cholinesterase Test System(Model 400) Instruction Manual. 2003. http://www.eqmresearch.com/Manual-E.pdf.

31. Gunnell D, Eddleston M, Phillips MR, Konradsen F: The global distribution of fatal pesticide self-poisoning: systematic review. BMC Public Health 2007, 7:357. doi:10.1186/1471-2458-7-357.

32. Mann JJ, Apter A, Bertolote J, Beautrias A, Currier D, Haas A, Hegerl U, Lonngvist J, Malone K, Marusic A, Mehlum L, Patton G, Phillips M, Rutz W, Rihmer Z, Schmidtke A, Shaffer D, Silverman M, Takashashi Y, Varnik A, Wasserman D, Yip P, Hendin H: Suicide prevention strategies: a systematic review. JAMA 2005, 294(16):2064-2074.

33. Ntow WJ, Gijzen HJ, Kelderman P, Drechsel P: Farmers perceptions and pesticide use practices in vegetable production in Ghana. Pest Manag Sci 2006, 62:356-365.

34. Heeren GA, Tyler J, Mandeya A: Agricultural chemical exposures and birth defects in Easter Cape Province, South Africa: a case-control study. Environ Health 2003, 2:11. doi:10.1186/1476-069X-2-11.

35. World Health Organization: Universal Access to Safe Blood and Blood Products for Transfusion. http://www.who.int/bloodsafety/en/. Accessed 15.09.2014.

doi:10.1186/1476-069X-13-98

Cite this article as: Neupane et al:: Pesticide use, erythrocyte acetylcholinesterase level and self-reported acute intoxication symptoms among vegetable farmers in Nepal: a cross-sectional study. Environmental Health 2014 13:98. 